УДК 676.1.054.1

\title{
ПОЛУЧЕНИЕ ДРЕВЕСНОВОЛОКНИСТЫХ ПЛИТ СУХИМ СПОСОБОМ ПРОИЗВОДСТВА, ИЗГОТОВЛЕННЫХ С ИСПОЛЬЗОВАНИЕМ ДРЕВЕСНОВОЛОКНИСТЫХ ОТХОДОВ ОТ ФОРМАТНО-ОБРЕЗНЫХ
}

\section{СТАНКОВ}

(С) И.М. Морозов ${ }^{1 *}$, В.А. Якимов ${ }^{2}$, Н.Г. Чистова ${ }^{1}$, Ю.Д. Алашкевич ${ }^{1,3}$, М.А. Зырянов

${ }^{1}$ Лесосибирский фрилиал Сибирского государственного технологического университета, ул. Победы, 29, Лесосибирск, 662543 (Россия),

e-mail: info@lfsibgtu.ru

${ }^{2}$ Сибирская пожарно-спасательная академия ГПС МЧС России, ул. Северная, 1, Железногорск, 662972 (Россия), e-mail: sekret_ugps@mail.ru

${ }^{3}$ Сибирский государственный технологический университет, пр. Muра, 82, Красноярск, 660049 (Россия), e-mail: sibstu@sibstu.kts.ru

В работе представлены результаты исследований подготовки древесноволокнистых отходов от форматнообрезных станков (ФОС) с целью дальнейшего их использования в готовой плитной продукции.

Объектом исследования настоящей работы является древесноволокнистая плита (ДВП), изготовленная сухим способом производства, предметом исследования - физические явления и процессы, характеризующие технологический процесс подготовки древесноволокнистых отходов от ФОС в получении ДВП сухим способом производства.

Достоверность результатов работы обеспечивается использованием комплекса современных взаимодополняющих физических, статистическо-математических методов исследований, а также лабораторными и производственными испытаниями, воспроизведением многочисленных опытов, статистической обработкой результатов исследований.

Выполнено планирование и реализация экспериментальных исследований процесса подготовки древесноволокнистых полуфабрикатов от форматнообрезных станков в изготовлении ДВП сухим способом производства. Проведен анализ статистическо-математических моделей и графических зависимостей, на основании которых научно обоснована возможность использования вторичного древесного волокна, подготовленного в роторно-ножевой мельнице МР-4, в изготовлении ДВП сухим способом производства без нарушения технологических процессов и без ухудшения качества готовой плиты.

Наилучшие показатели удельной поверхности древесных волокон 256400-245400 см²/г и прочности на статический изгиб 45-46 МПа были достигнуты при величине технологических параметров зазора между ножом и контрножом 3 мм и угле встречи контрножа с сырьем $225^{\circ}$.

В результате экономия древесного волокна в производстве ДВП составит $3 \%$ в общей прессмассе на единицу готовой продукции.

Ключевые слова: получение ДВП сухим способом производства, размол, роспуск, роторно-ножевая размольная мельница, плита, вторичное волокно, полуфабрикат.

\section{Введение}

В производстве древесноволокнистых плит отходы производства составляют около 10-12\%. В этом составе находятся: отходы инпресфайнера (верхний шнек рафинера), отходы от форматно-обрезных станков продольного и поперечного реза, брак готовой плитной продукции. Все эти отходы вывозятся на поли-

Морозов Иван Михайлович - аспирант кафедры технологии лесозаготовительных и деревоперерабатывающих производств, e-mail: ivan.morozov.les91@mail.ru

Окончание на с. 120 гоны - захоронения или сжигаются в местных ТЭЦ. При сжигании отходов ФОС образуются вредные соединения фенола, формальдегида и т.д. [1]. Данные вещества негативно влияют на окружающую среду и здоровье человека.

\footnotetext{
* Автор, с которым следует вести переписку.
} 
Иногда часть отходов находит свое применение в основном производстве. Однако из-за отсутствия технологий переработки вторичного волокна его повторное использование в производственном процессе в большинстве случаев оказывает негативное влияние на качество плиты. Для роспуска вторичного волокна в производстве ДВП используются либо дисковые, либо конические мельницы. Применение при подготовке вторичного волокна ножевых машин неприемлемо, на наш взгляд, по следующим причинам:

- ранее обработанное волокно подвергается дополнительной рубке в рабочих органах ножевых машин;

- исключается возможность использования вторичного волокна в полном объеме.

В данной работе рассматривается вопрос возможности подготовки и использования древесноволокнистых отходов от форматно-обрезных станков (ФОС) в получении ДВП сухим способом производства.

В задачи исследования входило:

1. Исследовать процесс роспуска древесноволокнистых отходов сухого способа производства ДВП в роторно-ножевой размольной установке, работающей по сухому способу размола.

2. Оценить показатели удельной поверхности вторичного древесного волокна, подготовленного сухим способом размола.

3. Изучить значения прочности на статический изгиб готовой плитной продукции с учетом использования в них отходов ФОС.

\section{Экспериментальная часть}

Исследования проводились в научно-технической лаборатории лесоперерабатывающей, целлюлозно-бумажной и химической технологий древесины Лесосибирского филиала Сибирского государственного технологического университета.

Ввиду сложности и малоизученности процесса размола древесноволокнистых материалов планирование и реализация эксперимента осуществлялись с использованием В-плана второго порядка [2].

На основании многочисленных предварительных исследований в качестве входных (управляемых) факторов эксперимента были выбраны следующие технологические параметры процесса: $\mathrm{z}$ - зазор между ножом и контрножом мельницы, мм; $\varepsilon$ - угол встречи контрножа с сырьем, град.

В качестве контролируемых факторов выбраны качественные характеристики волокна - удельная поверхность волокон (Уд) и физико-механические свойства древесноволокнистых плит - прочность на статический изгиб (б).

На основании исследований с целью установления количественной взаимосвязи исследуемых факторов выбраны интервалы и уровни их варьирования: $225 \leq \varepsilon \leq 135 ; 3 \leq \mathrm{z} \leq 9$.

Качественные показатели прочности и водопоглощения оценивались согласно ГОСТ 19592-80 Плиты древесноволокнистые. Методы испытаний.

Эксперимент реализовывался по следующему плану: фиксировались на определенных уровнях значения величины зазора между ножом и контрножом (z), при этом изменялись значения угла встречи ( $\varepsilon$ ) путем регулирования контрножа. Затем фиксировались значения угла встречи сырья с контрножом и варьировалось значение зазора. После чего оценивалось качество древесного волокна и физико-механические свойства готовых плит, полученных с учетом использования вторичного волокна.

Изучение поверхности волокон различной степени помола, мест их обрыва, а также структуры древесноволокнистого ковра и готовой плиты осуществляли при помощи поляризационно-интерференционного микроскопа BIOLAR с увеличением до 1500 крат [3].

В состав прессмассы для сухого способа производства ДВП входит основное сырье - $97 \pm 1 \%$ и отходы ФОС $-3 \pm 1 \%$. Породный состав исходного сырья для проведения исследования составлял $90 \pm 5 \%$

Якимов Вячеслав Анатольевич - аспирант

Чистова Наталья Геральдовна - профессор кафедры лесоинженерного дела, доктор технических наук, e-mail: chistova_n_g@mail.ru

Алашкевич Юрий Давыдович - заведующий кафедрой машин и аппаратов промышленных технологий, доктор технических наук, профессор, e-mail: mapt@sibstu.kts.ru Зырянов Михаил Алексеевич - доцент кафедры информационных и технических систем, кандидат технических наук, e-mail: zuryanov13@mail.ru хвойных и $10 \pm 5 \%$ лиственных древесного сырья.

При изготовлении плит сухим способом используют следующие основные материалы: смола карбамидоформальдегидная марки КФ-МТ-15, отвечающая требованиям ТУ 6-06-12-88 Смола карбамидоформальдегидная, марка КФ-МТ-15. Технические условия; аммоний хлористый технический, отвечающий требованиям ГОСТ 2210-73Е Аммоний хлористый. Технические условия; кар- 
бамид марки А в соответствии с ГОСТ 2081-92 Карбамид. Технические условия; а также парафины нефтяные, отвечающие требованиям ГОСТ 23683-89 Парафины нефтяные твердые. Технические условия. Изготовление древесноволокнистых плит сухим способом производства с учетом использования древесноволокнистых отходов от форматно-обрезных станков осуществлялось при всех прочих равных условиях, согласно ТУ 133-31-07-01.

Лабораторная установка МР-4, в которой осуществлялась подготовка древесноволокнистых отходов ФОС, представляет собой цилиндрический корпус, в котором установлен вал с закрепленными на нем ножами, расположенными в шахматном порядке. Отходы ФОС подаются в виде пятачков и волокна в зазор между контрножом и ножами, где происходит размол и роспуск в воздушной среде вторичного волокна. В результате древесное волокно режется, мнется, истирается, разбивается и фибриллируется [4-7].

Техническая характеристика устройства для размола МР-4 представлена в таблице.

Обработка результатов эксперимента осуществлялась в пакете программы STATISTICA-6. Расчет производился по КвазиТехническая характеристика устройства для размола MP-4

\begin{tabular}{l|c}
\hline \multicolumn{1}{c|}{ Наименование показателя } & Величина \\
\hline $\begin{array}{l}\text { Высота с питателем для крупных } \\
\text { габаритов измельчаемого материала, }\end{array}$ & 550 \\
мм & \\
Высота с питателем для широкого лис- & 310 \\
тового материала, мм & \\
Ширина машины, мм & 360 \\
Длина машины, мм & 750 \\
Электродвигатель трехфазного тока & \\
$\quad$ Напряжение, В & 220 \\
$\quad$ Мощность, кВт & 2 \\
$\quad$ Частота вращения ротора электро- & 1500 \\
$\quad$ двигателя, об/мин & \\
$\quad$ Частота вращения ведущего вала & 900 \\
$\quad$ устройства, об/мин & \\
Масса, кг & 55 \\
\hline
\end{tabular}
Ньютоновскому методу.

По результатам планирования, реализации и обработки экспериментальных данных были получены статистико-математические модели, адекватно описывающие процесс роспуска древесноволокнистых отходов:

- удельная поверхность вторичного волокна:

$$
\mathrm{Y}_{д}=320510+19078,2 \cdot \mathrm{z}-47579 \cdot \varepsilon-2535,7 \cdot \mathrm{z}^{2}+4288,3 \cdot \varepsilon^{2}+300,32 \cdot \mathrm{z} \cdot \varepsilon
$$

- прочность ДВП:

$$
\sigma=52,5+0,81 \cdot \mathrm{z}-3,6 \cdot \varepsilon-0,11 \cdot \mathrm{z}^{2}+0,33 \cdot \varepsilon^{2}+0,09 \cdot \mathrm{z} \cdot \varepsilon,
$$

\section{Обсуждение результатов}

По результатам статистико-математической обработки построены графические зависимости исследуемых факторов, наглядно представляющие полученные уравнения.

В качестве примера на рисунках 1 и 2 представлены графические зависимости удельной поверхности волокон древесноволокнистого полуфабриката (Уд) и прочности на изгиб готовых плит (б) с учетом использования вторичного волокна от варьирования значений технологических параметров размольной установки; угла встречи контрножа с сырьем ( $\varepsilon$ ) и значения зазора между ножом и контрножом (z).

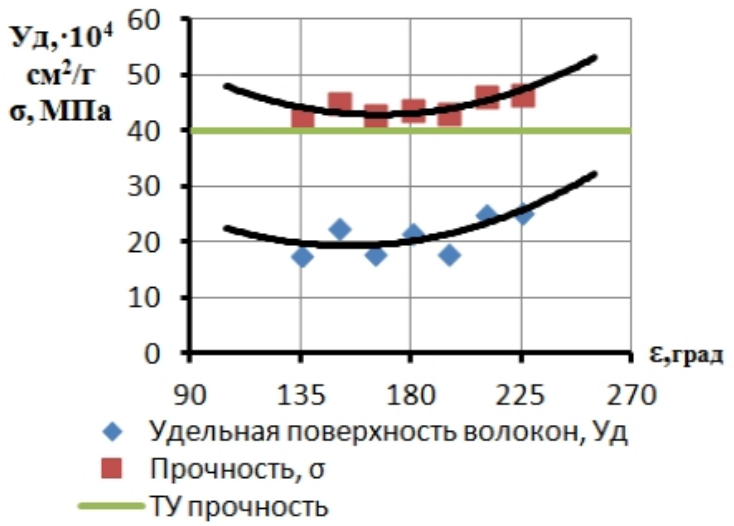

Рис. 1. Зависимость Уд и б от $\varepsilon$

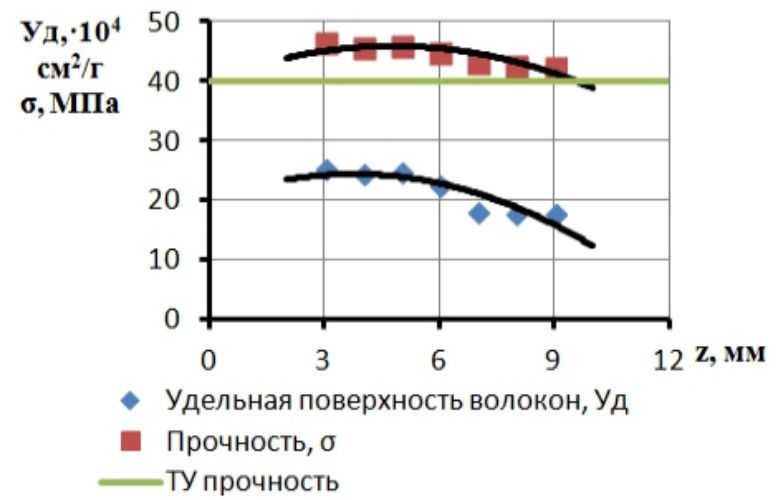

Рис. 2. Зависимость Уд и б от $\mathrm{z}$ 
Зависимости показателей удельной поверхности волокон и предела прочности на статический изгиб от изменений значений угла встречи контрножа с сырьем при фиксированной величине зазора между ножом и контрножом, равной 3 мм; от изменений значений зазора между ножом и контрножом с фиксированным углом встречи контрножа с сырьем, равным $\varepsilon=180^{\circ}$ при всех прочих равных условиях.

Анализируя графические зависимости, необходимо отметить, что исследуемые технологические факторы процесса размола показывают практически идентичное влияние на удельную поверхность волокон и прочность на статический изгиб готовой древесноволокнистой плиты.

Значения удельной поверхности волокон и прочности плиты на статический изгиб достигают максимального значения при $\varepsilon=225^{\circ}$ и $z=3$ мм. С дальнейшим увеличением или уменьшением исследуемых факторов происходит ухудшение качества древесноволокнистого полуфабриката и физико-механических показателей плиты.

Полученные в работе результаты можно объяснить тем, что при обработке древесноволокнистых отходов от форматнообрезных станков сухим способом размола в размольной установке МР-4 в процессе размола на волокна воздействуют ножевые усилия и аэродинамические явления. В результате такого размола, несмотря на то, что признаки ороговения волокна по-прежнему имеют место, на многих волокнах наблюдаются магистральные трещины, присутствует внешнее и внутреннее фибриллирование волокна (рис. 3), что хорошо видно при рассмотрении волокон в микроскоп. В результате происходит увеличение удельной поверхности отдельных волокон и, соответственно, прессмассы в целом.

Фибриллплазма группы А и мельштофф группы Б, получаемые в процессе предлагаемого способа подготовки сухим способом размола, способствуют увеличению удельной поверхности прессмассы в целом, соответственно улучшаются физико-механические свойства готовой продукции.

Поэтому в процессе исследования рассматривались и оценивались только массовые доли мелочи фибриллплазмы группы А и мельштоффа группы Б, так как именно они участвуют в образовании связей в плите $[8,9]$.

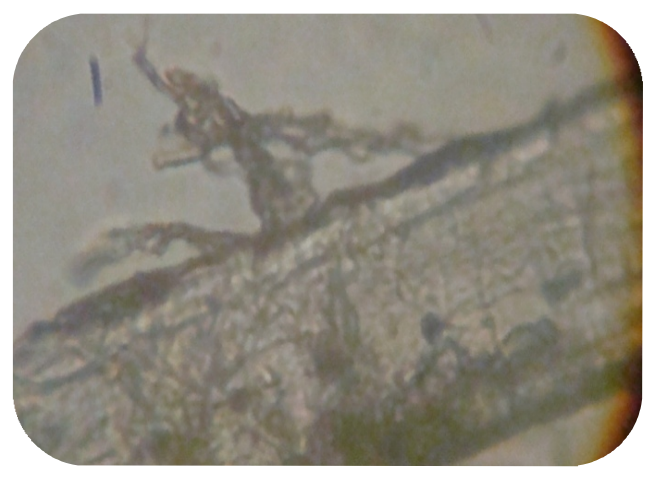

Рис. 3. Фибрилирование волокна при увеличении $\times 1500$

\section{Выводы}

Анализируя вышесказанное, можно сделать вывод, что подготовка древесноволокнистых отходов от форматно-обрезных станков на роторно-ножевой мельнице MP-4, работающей по сухому способу размола, возможна с дальнейшим использованием в основном производстве. В технологическом процессе получения ДВП сухим способом производства использование отходов ФОС позволит получить экономию древесного волокна, исключая сжигание и захоронение отходов от ФОС, способствуя тем самым решению экологических вопросов данного производства.

На основании полученных экспериментальных данных необходимо отметить, что наилучшие значения показателей удельной поверхности волокон равны 256400-245400 $\mathrm{cm}^{2} / \Gamma$ при величине зазора между ножом и контрножом 3 мм и величине угла встречи контрножа с сырьем $225^{\circ}$. При тех же самых значениях исследуемых входных технологических факторов, наилучшие значения показателя предела прочности на статический изгиб готовых плит ДВП равны 45-46 МПа.

Таким образом, проведенные исследования и их анализ дают основание полагать, что вторичное волокно, подготовленное предлагаемым способом размола, можно и должно использовать в полном объеме образования при изготовлении ДВП сухим способом производства. В результате экономия древесного волокна составит $3 \%$ в общей прессмассе на единицу готовой продукции. 


\section{Список литературы}

1. Леонович А.А., Шелоумов А.В. Снижение пожарной опасности древесных материалов, изделий строительных конструкции. СПб., 2002. 59 с.

2. Пижурин А.А., Пижурин А.А. Моделирование и оптимизация процессов деревообработки. М., 2004. 375 с.

3. Морозов И.М., Чистова Н.Г. Совершенствование технологического процесса производства древесноволокнистых плит // Экология, рациональное природопользование и охрана окружающей среды. 2014. Т. І. С. 261-265.

4. Петрушева Н.А. Подготовка вторичного волокна при производстве древесноволокнистых плит мокрым способом : дис. ... канд. техн. наук. Красноярск, 2003. 115 с.

5. Зырянов М.А. Получение полуфабрикатов в одну ступень размола для производства древесноволокнистых плит мокрым способом : дис. ... канд. техн. наук. Красноярск, 2012. 167 с.

6. Чистова Н.Г. Размол древесноволокнистой массы на промышленных установках при производстве ДВП : дис. ... канд. техн. наук. Красноярск, 2000. 170 с.

7. Жуковский Н.Е. Гидродинамика. М., 1949. Т. 2. 763 с.

8. Чистова Н.Г. Переработка древесных отходов в технологическом процессе получения древесноволокнистых плит: дис. ... д-ра техн. наук. Красноярск, 2010. 415 с.

9. Морозов И.М., Чистова Н.Г. Экологический фактор рециклинга древесноволокнистых отходов плитного производства // Экология, рациональное природопользование и охрана окружающей среды. 2013. Т. І. С. 351-355.

Поступило в редакцию 2 октября 2015 г.

После переработки 26 ноября 2015 г. 
Morozov I.M. ${ }^{1 *}$, Yakimov V.A. ${ }^{2}$, Chistova N.G. ${ }^{1}$, Alashkevich Iu.D. ${ }^{1,3}$, Zyrianov M.A. ${ }^{l}$ GETTING DRY FABERBOARDS PRODUCTION, MANUFACTURE FIBER USING WOOD WASTE FROM MACHINES

${ }^{I}$ Lesosibirsky branch of the Siberian State Technological University, Pobedy st., 29, Lesosibirsk, 662543 (Russia), e-mail: info@lfsibgtu.ru

${ }^{2}$ Siberian Fire and Rescue Academy State Fire Service of the Ministry of the Russian Federation for Civil Defense, Emergencies and Elimination of Consequences of Natural Disasters, Severnaia st., 1, Zheleznogorsk, 662972 (Russia), e-mail:info@lfsibgtu.ru

${ }^{3}$ Siberian State Technological University, Mira ave., 82, Krasnoyarsk, 660049 (Russia), e-mail: sibstu@sibstu.kts.ru

The paper presents the results of studies preparation of wood waste from the sliding table machines (FOS) for the purpose of their further use in the finished product of plate.

The object of study of this work are fibreboard (DVP), the dry method of production, the subject of research - physical phenomena and processes that characterize the process of preparation of wood waste from the FOS in obtaining hardboard dry process production.

Reliability of results is provided by using a complex of modern complementary physical, statistical and mathematical methods of research, as well as laboratory and production tests, the playback of numerous experiments, statistical processing of the results of research.

Achieved planning and implementation of experimental studies of the process of preparation of the semi-finished woodformatnoobreznyh machines to manufacture hardboard dry process production. The analysis of statistical and mathematical models and a graph on the basis of which scientifically proved the possibility of using recycled wood fibers prepared in rotary knife mill MP-4, in the manufacture of hardboard dry process without disrupting manufacturing processes and without deterioration of the quality of the finished board.

The best performance of the specific surface of the fibers $256400-245400 \mathrm{~cm}^{2} / \mathrm{g}$, and the static bending strength of 45 $46 \mathrm{MPa}$ were obtained when the value of the gap between the process parameters and the anvil $3 \mathrm{~mm}$ and impact angle with the feed anvil $225^{\circ}$.

As a result of the savings in the production of wood fiber hardboard will be $3 \%$ of the total pressmasse per unit of finished product.

Keywords: dry faberbords, grind, dissolution, rotor and knife mill, plate, secondary fiber, semi-finished product.

\section{References}

1. Leonovich A.A. Snizhenie pozharnoi opasnosti drevesnykh materialov, izdelii i stroitel'nykh konstruktsii. [Reduced fire hazard wood-based materials, products and building structures]. St. Petersburg, 2002, 59 p. (in Russ.).

2. Pizhurin A.A., Pizhurin A.A. Modelirovanie $i$ optimizatsiia protsessov derevoobrabotki. [Simulation and Optimization of wood]. Moscow, 2004, 375 p. (in Russ.).

3. Morozov I.M., Chistova N.G. Ekologiia, ratsional'noe prirodopol'zovanie i okhrana okruzhaiushchei sredy, 2014, vol. I, pp. 261-265. (in Russ.).

4. Petrusheva N.A. Podgotovka vtorichnogo volokna pri proizvodstve drevesnovoloknistykh plit mokrym sposobom : dis. ... kand. tekhn. nauk. [Preparation of recycled fibers in the production of fiberboard wet Dissertation of the candidate of technical sciences]. Krasnoyarsk, 2003, 115 p. (in Russ.).

5. Zyrianov M.A. Poluchenie polufabrikatov v odnu stupen' razmola dlia proizvodstva drevesnovoloknistykh plit mokrym sposobom : dis. ... kand. tekhn. nauk. [Production of semi-finished grinding in one step for the production of wet process fibreboard Dissertation of the candidate of technical sciences]. Krasnoyarsk, 2012, 167 p. (in Russ.).

6. Chistova N.G. Razmol drevesnovoloknistoi massy na promyshlennykh ustanovkakh pri proizvodstve DVP : dis. ... kand. tekhn. nauk. [Grinding wood fiber mass at industrial plants in the production of fiberboard Dissertation of the candidate of technical sciences]. Krasnoyarsk, 2000. 170 p. (in Russ.).

7. Zhukovskii N.E. Gidrodinamika. [Hydrodynamics]. Moscow, 1949, vol. 2, 763 p. (in Russ.).

8. Chistova N.G. Pererabotka drevesnykh otkhodov $v$ tekhnologicheskom protsesse polucheniia drevesnovoloknistykh plit : dis.... d-ra tekhn. nauk. [Recycling wood waste in the process producing fibreboard: the dissertation of the doctor of technical sciences]. Krasnoyarsk, 2010, 461 p. (in Russ.).

9. Morozov I.M., Chistova N.G. Ekologiia, ratsional'noe prirodopol'zovanie i okhrana okruzhaiushchei sredy, 2013, vol. I, pp. 351-355. (in Russ.).

Received October 2, 2015

Revised November 26, 2015

\footnotetext{
* Corresponding author.
} 